\title{
Electrocatalytic Oxidation of Venlafaxine at a Multiwall Carbon Nanotubes-Ionic Liquid Gel Modified Glassy Carbon Electrode and Its Electrochemical Determination
}

\author{
Ling Ding, ${ }^{\text {a }}$ Lei Li, ${ }^{\mathrm{b}}$ Wei You, ${ }^{\mathrm{a}}$ Zuo-Ning Gao, ${ }^{\mathrm{a}, *}$ and Tian-Lin Yang ${ }^{\mathrm{a}}$ \\ ${ }^{a}$ College of Chemistry and Chemical Engineering, Ningxia University, Yinchuan, 750021, People's Republic of China \\ ${ }^{b}$ Liaoning Research Institute of Light Industry, Shenyang 110004, People's Republic of China
}

RECEIVED JANUARY 15, 2014; REVISED DECEMBER 11, 2014; ACCEPTED FEBRUARY 10, 2015

\begin{abstract}
The electrocatalytic oxidation of venlafaxine (VEN) was investigated at a glassy carbon electrode (GCE), the modified electrode by a gel containing multiwall carbon nanotubes (MWCNTs) and a room-temperature ionic liquid (RTIL), 1-butyl-3-methylimidazolium hexafluorophate $\left(\mathrm{BMIMPF}_{6}\right)$ in $0.10 \mathrm{~mol} \mathrm{~L}^{-1}$ phosphate buffer solution (PBS, pH 6.8). It was found that an irreversible anodic oxidation peak of VEN with the peak potential $\left(E_{\mathrm{pa}}\right)$ as $0.780 \mathrm{~V}$ appeared at MWCNTs-RTIL/GCE. The electrode reaction process was a diffusion-controlled one and the electrochemical oxidation involved two electrons transferring and two protons participation. Furthermore, the charge-transfer coefficient $(\alpha)$, and the electrode reaction rate constant $\left(k_{\mathrm{f}}\right)$ of VEN were found to be 0.91 and $3.04 \times 10^{-2} \mathrm{~s}^{-1}$, respectively. Under the optimized conditions, the electrocatalytic oxidation peak currents were linearly dependent on the concentration of VEN in the concentration range from $2.0 \times 10^{-6} \mathrm{~mol} \mathrm{~L}^{-1} \sim 2.0 \times 10^{-3} \mathrm{~mol} \mathrm{~L}^{-1}$ with the limit of detection $(S / N=3)$ as $1.69 \times 10^{-6} \mathrm{~mol} \mathrm{~L}^{-1}$. The proposed method has been successfully applied in the electrochemical quantitative determination of VEN content in commercial venlafaxine hydrochloride capsules and the determination results could meet the requirement of the quantitative determination.
\end{abstract}

Keywords: venlafaxine, electrocatalytic oxidation, MWCNTs-RTIL/GCE, GCE electrochemical determination

\section{INTRODUCTION}

Venlafaxine (VEN, 1-2-(dimethylamino)-1-(4-methoxyphenyl)ethylcyclohexanol, chemical structural formula see Figure 1), is a new antidepressant, which selectively inhibits re-uptake of norepinephrine and serotonin, and slightly inhibits re-uptake of dopamine and without significant affinity for muscarinic, histaminergic or $\alpha_{1}$-adrenergic receptors. ${ }^{1-3}$ It also has a good treatment of anxiety associated with depression, generalized anxiety disorder and obsessive-compulsive disorder as foreign test reported. ${ }^{4,5}$ However, an overdose of VEN results in the most common symptoms such as depression, serotonin toxicity, seizure, or cardiac conduction abnormalities. Hence, their determination is of great significance. ${ }^{6-8}$

To the best of our knowledge, the main research methods of VEN including high performance liquid chromatography, ${ }^{9-11}$ high-performance liquid chromatography-electrospray ionization mass spectrometry (HPLC-MS/ESI), ${ }^{12,13}$ high-performance liquid chroma- tography and spectrofluorimetry, ${ }^{14-16}$ liquid chromatography-mass spectrometry, ${ }^{17-22}$ liquid chromatography, ${ }^{23,24}$ spectrofluorimetry, ${ }^{25}$ gas chromatography-mass spectrometry ${ }^{26}$ reversed phase high-performance liquid chromatography, ${ }^{27-29}$ capillary electrophoresis, ${ }^{30}$ and the electrochemical methods. ${ }^{31-34}$ From what is mentioned above, various electrochemical methods have been developed for the quantitative determinations of VEN such as square wave voltammetry on hanging mercury electrode, ${ }^{31}$ adsorptive stripping voltammetry on

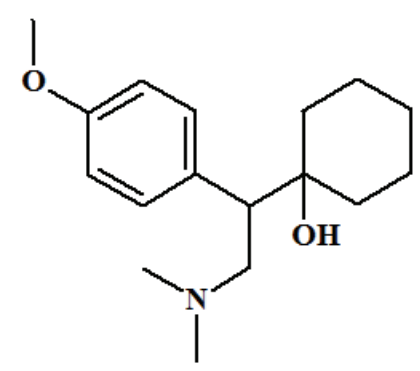

Figure 1. Chemical structure formula of VEN.

\footnotetext{
* Author to whom correspondence should be addressed. (E-mail: gaozn@nxu.edu.cn)
} 
mercury film modified glassy carbon electrode, ${ }^{32}$ adsorptive stripping differential pulse voltammetry on nafion-carbon nanotube modified glassy carbon electrode, ${ }^{33}$ and electrocatalytic oxidation and electrochemical determination of venlafaxine at acetylene blackionic liquid modified glassy carbon electrode. ${ }^{34}$ However, the electrocatalytic oxidation and electrochemical determination of VEN at multi-wall carbon nanotubesionic liquid gel modified glass carbon electrode (MWCNTs-RTIL/GCE) has not been reported in the literature to the best of our knowledge.

Carbon nanotubes (CNTs) have started a new era for the development of novel electrode materials due to their amazing structural, mechanical, electrical and physical properties. ${ }^{35-40}$ Moreover, CNTs have many other novel properties such as small size, large surface area, high electrical conductivity, high mechanical strength, interface effect and the other characteristics. Their subtle electronic properties suggest that CNTs have the ability to promote charge-transfer reactions when used as electrode modifying materials. ${ }^{41}$ Roomtemperature ionic liquids (RTILs) are molten organic salts consisting entirely of ions that exist in the liquid state around room temperature. ${ }^{42}$ They have excellent chemical and physical properties such as good chemical and thermal stability, wide electrochemical windows and high ionic conductivity. ${ }^{43-46}$ When a gels is made by grinding the mixture of imidazolium ion-based RTILs and pristine single-walled CNTs, CNTs have good performance of electrochemical characteristics as the phenomenon of agglomeration and cross-linking of CNTs can be mediated by RTILS because of the "cation- $\pi$ " of strong interactions between RTILs and CNTs. ${ }^{47,48}$ Thus, the combination of the RTILs and CNTs can get a favorable fabrication of the modified electrode which can be successfully applied in the catalysis of bioelectrochemical reaction, fabrication of biosensors and the determination of the various biomolecules. $^{49}$

As a continuation of our previous work, ${ }^{34,50}$ we found that the oxidation peak potential of VEN shifted to positive slightly at MWCNTs-RTIL/GCE and the peak current increased by almost two times in contrast to that at MWCNTs/GCE, and the oxidation peak potential shifted to negative slightly and the peak current increased by almost eight times in contrast to that at GCE which indicated that MWCNTs-RTIL can catalyze VEN electrochemical oxidation reaction very well. The electrochemical behaviors and electrochemical kinetics of VEN were investigated at MWCNTs-RTIL/GCE by cyclic voltammetry $(\mathrm{CV})$, chronoamperometry $(\mathrm{CA})$ and the square wave voltammetry (SWV). At the same time, a quantitative electrochemical determination of VEN content in commercial Venlafaxine hydrochloride capsules was determined and the experimental results can meet the requirement of the quantitative determination.

\section{EXPERIMENTAL}

\section{Apparatus}

All electrochemical experiments were carried out using an Electrochemistry Workstation CHI660A (CH Instrument, USA). A personal computer was used for data storage and processing. The working electrodes were a CHI104 GCE with $3 \mathrm{~mm}$ diameter, multi-wall carbon nanotube modified glassy carbon electrode (MWCNTs/GCE), and a glassy carbon electrode modified by multi-wall carbon nanotube and the room temperature ionic liquid (MWCNTs-RTIL/GCE), a platinum wire as the auxiliary electrode and a saturated calomel electrode (SCE) as the reference electrode, respectively. All potentials measured and reported in this work were versus a SCE.

\section{Reagents}

Venlafaxine (Batch No. 201091102, purity > 99 \%) was from Jiangxi Synergy Pharmaceutical Co. Ltd. (Jiangxi province, China). Venlafaxine hydrochloride capsules (Batch No. 2066157) was from Chengdu Brilliant Pharmaceutical Co. Ltd. (Sichuan province, China). MWCNTs (provided from Prof. Fei Wei, Chemical Engineering College of Tsinghua University, China) were functionalized to give carboxylic carbon nanotubes following the procedure reported. ${ }^{51}$ 1-Butyl-3-methylimidazolium hexafluorophate (BMIMPF6, Shanghai Chengjie Chemical Co. Ltd, China; Purity > 99\%). 0.10 mol L ${ }^{-1} \mathrm{Na}_{2} \mathrm{HPO}_{4}-\mathrm{NaH}_{2} \mathrm{PO}_{4}$ buffer solution (PBS, $\mathrm{pH}$ 6.8) was used as the supporting electrolyte. Other reagents used were of analytical grade. All solutions were prepared by doubly distilled water and thoroughly flushed with high purity nitrogen that was used to remove oxygen for $5 \mathrm{~min}$ from the solutions in the electrochemical cell. All experiments were carried out at room temperature.

\section{Fabrication of the Modified Mlectrodes}

A glassy carbon electrode was polished with $0.3 \mu \mathrm{m}$ $\alpha-\mathrm{Al}_{2} \mathrm{O}_{3}$ slurry on the polishing micro-cloth, rinsed thoroughly with the double distilled water and ultrasonic successively in acetone and double distilled water for $3 \mathrm{~min}$ to remove any remaining polishing alumina.

$1 \mathrm{mg}$ of functionalized MWCNTs were dispersed into $2 \mathrm{~mL}$ N,N-dimethylformamide (DMF) / H2O (1 : 1) aqueous solution with the aid of ultrasonic stirring for 15 min to give a $0.50 \mathrm{mg} \mathrm{mL}^{-1}$ homogeneous black suspension, and then $8 \mu \mathrm{L}$ of MWCNTs dispersion was dropped on GCE surface with a micro-syringe and the 
solvent was evaporated under infrared lamp to obtain MWCNTs/GCE.

$6 \mathrm{mg}$ MWCNTs mixed with $100 \mu \mathrm{L} \mathrm{BMIMPF}_{6}$ was ground for about $20 \mathrm{~min}$ in a mortar to give a viscous CNTs-RTIL gel, and then a proper amount of the gel was transferred on the cleaned electrode surface by mechanically rubbing, thus the MWCNTs-RTIL/GCE was fabricated.

\section{RESULTS AND DISCUSSION}

\section{The Electrochemical Impedance Spectroscopy (EIS) of GCE and the Modified Electrodes}

The EIS could generally reflect the surface properties of the modified electrode during the fabrication process. ${ }^{52}$ By using $\mathrm{Fe}(\mathrm{CN})_{6}{ }^{3-/ 4-}$ redox couples as an electrochemical probe, the Nyquist plots of the different electrodes were shown in Figure 2. With the frequencies range from $1 \mathrm{~Hz}$ to $100 \mathrm{kHz}$, the EIS plots consist of two parts: one is the linear part at lower frequencies which represent the diffusion-limited process; the other one is a semicircle portion observed at the higher frequencies corresponding to the electron-transfer-limited process. Generally, the diameter of the semicircle is usually equal to the resistance of electron transferring (Ret), at high frequencies near the origin, MWCNTs-RTIL/GCE represented an obvious smaller semicircle (curve $\mathbf{c}$ in Figure 2) than that of the GCE (curve a in Figure 2) and that of MWCNTs/GCE (curve b in Figure 2), which related to a good ionic conductivity and the least resistance of electron transferring of MWCNTs-RTIL/GCE. At low frequencies, MWCNTs-RTIL/GCE represented a linear tail with a maximal slope (curve $\mathbf{c}$ in Figure 2) among the three kinds of the electrodes which indicated that MWCNTs-RTIL/GCE obviously improved the diffusion of ferricyanide toward the electrode surface, in

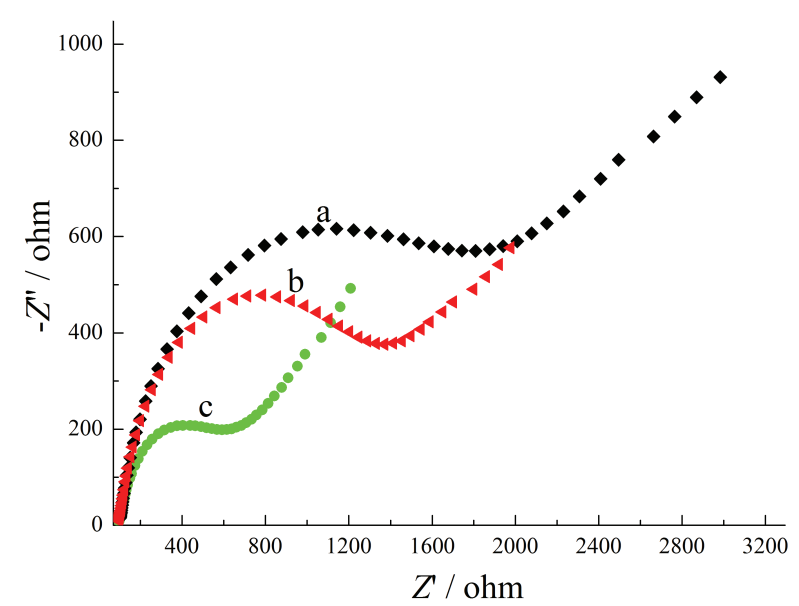

Figure 2. EIS at GCE (a); MWCNTs/GCE (b); and MWCNTs-RTIL/GC (c) in $1.0 \times 10^{-3} \mathrm{~mol} \mathrm{~L}^{-1} \mathrm{Fe}(\mathrm{CN})_{6}^{3-/ 4}+$ $1.0 \mathrm{~mol} \mathrm{~L}^{-1} \mathrm{KCl}$. The frequency range is $1 \sim 105 \mathrm{~Hz}$. agreement with EIS theory. ${ }^{53}$ The experimental results of EIS indicated that the MWCNTs-RTIL/GCE could promote the electron transferring rate of $\left[\mathrm{Fe}(\mathrm{CN})_{6}\right]^{3-14}$ effectively.

\section{Cyclic Voltammetric Behaviors of VEN}

The cyclic voltammetric behaviors of $2.0 \times 10^{-4} \mathrm{~mol} \mathrm{~L}^{-1}$ of VEN at MWCNTs-RTIL/GCE, MWCNTs/GCE and GCE had been investigated with the scan rate of $50 \mathrm{mV} \mathrm{s}^{-1}$ in $0.10 \mathrm{~mol} \mathrm{~L}^{-1}$ of $\mathrm{NaH}_{2} \mathrm{PO}_{4}-\mathrm{Na}_{2} \mathrm{HPO}_{4}$ solution ( $\mathrm{PBS}, \mathrm{pH}$ 6.8) over the potential windows of $0.30 \mathrm{~V} \sim 1.20 \mathrm{~V}$ as shown in Figure 3. From the curve $\mathbf{c}$ in Figure 3, it can be seen that an irreversible oxidation peak of VEN with the peak potential $\left(E_{\mathrm{pa}}\right)$ as $0.78 \mathrm{~V}$ appeared at MWCNTs-RTIL/GCE. It found that the oxidation peak potential of VEN at MWCNTsRTIL/GCE shifted to negative slightly and the peak current increased by almost three times in contrast to that at GCE (curve a in Figure 3), and the oxidation peak potential shifted to positive slightly and the peak current increased by over one times in contrast to that at MWCNTs/GCE (curve b in Figure 3). It shown that the oxidation peak potential shifted to positive slightly may have some relationship with the viscosity of RTIL. The electrochemical oxidation of VEN can be improved at MWCNTs-RTIL/GCE and it is an irreversible electrocatalytic oxidation process in the experimental results. The probable catalytic mechanism is that MWCNTs with nano-scaled dimensions have large surface area to provide more reaction sites for electrocatalytic oxidation and to promote the electron exchange rate of $\mathrm{VEN} .^{41}$ In addition, RTIL with high ionic conductivity can further promote the electron transferring, ${ }^{45,46}$ and then the MWCNTs are untangled after treated with the RTIL, mainly because of cross-linking of the nano-tube bundles mediated by local molecular ordering of RTIL

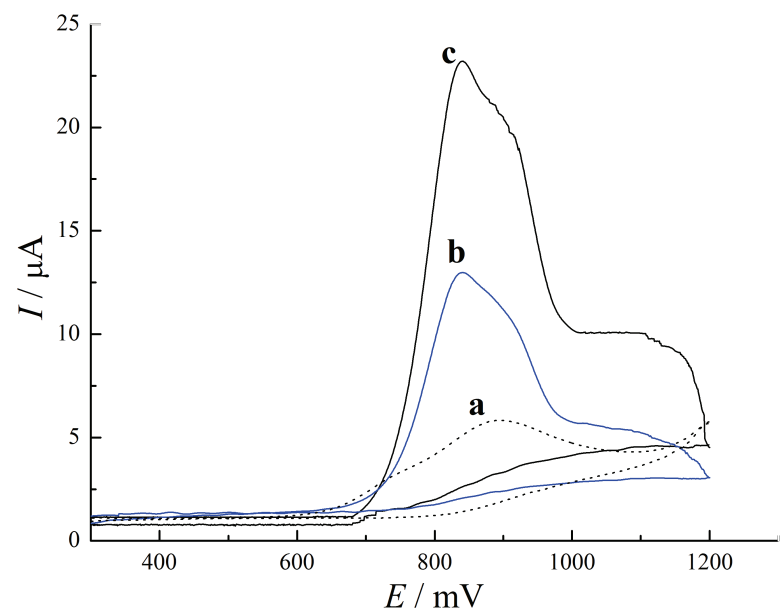

Figure 3. $\mathrm{CVs}$ of $2.0 \times 10^{-4} \mathrm{~mol} \mathrm{~L}^{-1} \mathrm{VEN}$ at GCE (a), MWCNTs/GCE (b) and MWCNTs-RTIL/GCE (c) containing $0.10 \mathrm{~mol} \mathrm{~L}^{-1}$ PBS. Scan rate: $50 \mathrm{mV} \mathrm{s}^{-1}$. 
resulting from the "cation- $\pi$ " interactions between imidazolium and nano-tubes. ${ }^{47,48}$ Therefore, MWCNTsRTIL gel can act as a catalyst to improve the electron transferring rate, and then to promote the electrocatalytic oxidation process of VEN very well. However, no corresponding reduction peak was observed on the reverse scan indicating the irreversibility of electrochemical oxidation of VEN. The effect of scan rate on the electrochemical behaviors of VEN at GCE, MWCNTs/GCE and MWCNTs-RTIL/GCE were investigated by cyclic voltammetry $(\mathrm{CV})$ under the scan rate from $10 \mathrm{mV} \mathrm{s}^{-1}$ to $1000 \mathrm{mV} \mathrm{s}^{-1}$. With the scan rate increasing, both the peak currents increased and the peak potentials shifted positively. The oxidation peak currents $\left(I_{\mathrm{p}}\right)$ versus the square roots of the scan rate $\left(v^{1 / 2}\right)$ was a straight line, their linear regression equations were expressed as $I_{\mathrm{pa}} / \mu \mathrm{A}=5.20+1.76 v^{1 / 2}$, $I_{\mathrm{pa}} / \mu \mathrm{A}=8.68+6.36 v^{1 / 2}$ and $I_{\mathrm{pa}} / \mu \mathrm{A}=2.40+3.37 v^{1 / 2}$ with the correlation coefficients $(R)$ as $0.9980,0.9990$ and 0.9980 at GCE, MWCNTs/GCE and MWCNTsRTIL/GCE, respectively. The experimental results were expected that the electrochemical oxidation processes of VEN at GCE, MWCNTs/GCE and MWCNTsRTIL/GCE are a diffusion-limited electrode reaction processes.

\section{The Effects of Experimental Conditions}

The effect of the various kinds of electrolytic solutions on the catalytic oxidation peak currents and potentials of VEN have been conducted by $\mathrm{CV}$. The voltammetric behaviors of VEN at scan rate $50 \mathrm{mV} \mathrm{s}^{-1}$ had been investigated in different electrolytic solutions such as aqueous $\mathrm{NaCl}, \mathrm{Na}_{2} \mathrm{SO}_{4}, \mathrm{NaNO}_{3}, \mathrm{NaAc}, \mathrm{NaAc}-\mathrm{HAc}$, B-R and $\mathrm{Na}_{2} \mathrm{HPO}_{4}-\mathrm{NaH}_{2} \mathrm{PO}_{4}$ (PBS) buffer solutions. The experimental results showed that VEN had a welldefined electrochemical behavior in $0.10 \mathrm{~mol} \mathrm{~L}^{-1}$ of PBS. Therefore, $0.10 \mathrm{~mol} \mathrm{~L}^{-1}$ of PBS was chosen as a supporting electrolyte.

The effect of the amount of the MWCNT on the oxidation peak currents of VEN was studied. The experimental results revealed that the oxidation peak currents of VEN increased gradually with the increasing amount of the MWCNT from $2 \mu \mathrm{L} \sim 8 \mu \mathrm{L}$, and then remained basically unchanged when the amount of the MWCNT increased from $8 \mu \mathrm{L} \sim 13 \mu \mathrm{L}$, but it was reduced when the amount of the MWCNT increased further. Therefore, the appropriate amount of the MWCNT is about $8 \mu \mathrm{L}$. BMIMPF B $_{6}-\mathrm{MWCNT}$ composite with different ratio was investigated by $\mathrm{CV}$ in $2.0 \times 10^{-4} \mathrm{~mol} \mathrm{~L}^{-1} \mathrm{VEN}$ with $0.10 \mathrm{~mol} \mathrm{~L}^{-1}$ of PBS which indicated that the peak currents of VEN remained constant basically. However, when the amounts of RTIL are too much or little, it can not form a very good paste for fabricating the $\mathrm{BMIMPF}_{6}-\mathrm{MWCNT} / \mathrm{GCE}$. Their

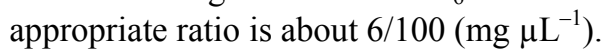

VEN electrochemical oxidation is a pH-dependent as shown in Figure 4. The effect of solution $\mathrm{pH}$ on the oxidation peak current and peak potential for $2.0 \times 10^{-4} \mathrm{~mol} \mathrm{~L}^{-1} \mathrm{VEN}$ on MWCNTs-RTIL/GCE was studied by $\mathrm{CV}$ over the $\mathrm{pH}$ range from $4.0 \sim 12.0$. Experimental results show that with the increasing $\mathrm{pH}$, the oxidation peak potentials of VEN on MWCNTsRTIL/GCE shifted linearly to negative over the $\mathrm{pH}$ range from $4.0 \sim 9.0$. The relationship between the oxidation peak potentials and the solution $\mathrm{pH}$ could be fit to the equation as $E_{\mathrm{p}} / \mathrm{mV}=1309.5-62.3 \mathrm{pH}$ with a correlation coefficient as 0.9980 . Since the electrochemical oxidation of VEN is known to occur by a two electron transferring, ${ }^{33}$ thus the number of protons involved were also predicted to be two according to the equation of $E_{\mathrm{p}} / \mathrm{mV}=E_{0}-(59 \mathrm{~m} / \mathrm{n}) \mathrm{pH}$. The results indicated that the electrochemical oxidation of VEN on MWCNTsRTIL/GCE is an irreversible electrochemical oxidation process taking part in by two electrons and two protons. The oxidation peak potentials of VEN kept basically unchanged when $\mathrm{pH}>9.0$. The oxidation peak currents of VEN decreased with increasing $\mathrm{pH}$ over the $\mathrm{pH}$ range from $4.0 \sim 8.5$ and it kept basically constant from $8.5 \sim$ 10.5 , but it decreased from $10.5 \sim 12.0$.

\section{Electrochemical Kinetics}

\section{Charge Transferring Coefficient $\alpha$}

$\mathrm{CV}$ determinations of $2.0 \times 10^{-4} \mathrm{~mol} \mathrm{~L}^{-1} \mathrm{VEN}$ on MWCNTs-RTIL/GCE were investigated under scan rate from $10 \mathrm{mV} \mathrm{s}^{-1} \sim 1000 \mathrm{mV} \mathrm{s}^{-1}$ in the potential windows from $0.30 \mathrm{~V} \sim 1.20 \mathrm{~V}$. For an irreversible diffusioncontrolled one, the peak potential $\left(E_{\mathrm{p}}\right)$ is proportional to the logarithm of potential scan rate $(\log v)$ with the following equation: ${ }^{54}$

$$
E_{\mathrm{p}}=\frac{b}{2} \log v+\text { constant }
$$

From the equation, we know that the slope of $E_{\mathrm{p}}$ $v s . \log v$ plot is $b / 2$, where $b$ indicates the Tafel slope.

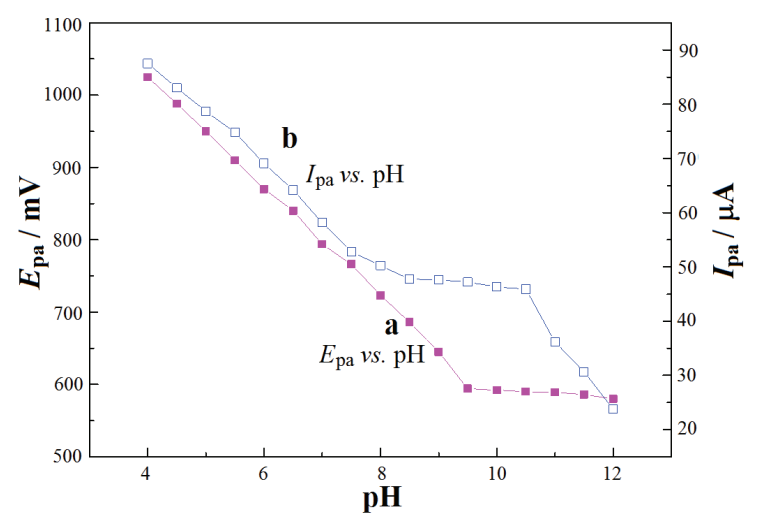

Figure 4. Dependence of $E_{\mathrm{p}}(\mathbf{a})$ and $I_{\mathrm{p}}(\mathbf{b})$ on $\mathrm{pH}$. 
Their linear regression equations expressed as $E_{\mathrm{pa}} / \mathrm{mV}$ $=674.9+71.8 \log \left(v / \mathrm{mV} \mathrm{s}^{-1}\right), E_{\mathrm{pa}} / \mathrm{mV}=571.6+$ $139.4 \log \left(v / \mathrm{mV} \mathrm{s}^{-1}\right)$ and $E_{\mathrm{p}} / \mathrm{mV}=508.5+161 \log (v$ $\left./ \mathrm{mV} \mathrm{s}^{-1}\right)$ with a correlation coefficients $(R)$ as 0.9990 , 0.9956 and 0.9980 at GCE, MWCNTs/GCE and MWCNTs-RTIL/GCE. A value of $b=2 \times \partial E_{\mathrm{p}} / \partial(\log v)=$ $143.6 \mathrm{mV}, 278.8 \mathrm{mV}$ and $322.2 \mathrm{mV}$, were obtained. As we know the number of the electron transferring $(n)$ of VEN is $2,{ }^{33}$ so the charge transferring coefficient $(\alpha)$ can be obtained according to the equation $b=2.303 R T / n$ $(1-\alpha) F$. The calculated charge transferring coefficients $(\alpha)$ of VEN on the GCE, MWCNTs/GCE and MWCNTs-RTIL/GCE see Table 1.

\section{The Electrode Reaction Rate Constant $k_{f}$}

The electrode reaction rate constant $\left(k_{\mathrm{f}}\right)$ can be determined by chronoamperometry (CA) using the following equation: ${ }^{55}$

$$
I(t)=n F A k_{\mathrm{f}} C[1-2 H \sqrt{t / \pi}]
$$

in which, $H=k_{\mathrm{f}} / D_{\mathrm{ox}}^{1 / 2}+k_{\mathrm{b}} / D_{\mathrm{Rd}}^{1 / 2}$. For the totally irreversible electrochemical reaction, the value of $k_{\mathrm{b}}$ is 0 , therefore $H=k_{\mathrm{f}} / D_{\mathrm{ox}}^{1 / 2}$. When $t$ approaches to 0 , the plot of $I(t) v s t^{1 / 2}$ gives a good straight line. Therefore, $k_{\mathrm{f}}$ of VEN on GCE, MWCNTs/GCE and MWCNTsRTIL/GCE can be calculated from the slopes and the intercepts of CA curves as shown in Table 1 as well.

In order to check the electrochemical response of MWCNTs-RTIL/GCE for VEN, the time-steady state current response curves was determined and the experimental results are shown in Figure 5. The current response signal of MWCNTs-RTIL/GCE is proportional to VEN concentration, response time is less than five seconds, and the least response concentration is $2.0 \times 10^{-6} \mathrm{~mol} \mathrm{~L}^{-1}$ which can be used in VEN electrochemical quantity determination with both the low detection limit and the high sensitivity.

\section{Electrochemical Determination Application}

\section{Optimization of Experimental Conditions of SWV}

The square wave voltammetric response markedly depends on the parameters of the excitement signals. Therefore, optimization of the pulse amplitude, the frequency, and the scan potential increment were investigated in the experiment. The dependence of the

Table 1. Kinetic parameters for VEN at GCE, MWCNTs/GCE and MWCNTs-RTIL/GCE

\begin{tabular}{ccc}
\hline Electrodes & $\alpha$ & $k_{f} / \mathrm{s}^{-1}$ \\
\hline GCE & 0.79 & $2.20 \times 10^{-3}$ \\
MWCNTs/GCE & 0.87 & $1.54 \times 10^{-2}$ \\
MWCNTs-RTIL/GCE & 0.91 & $3.04 \times 10^{-2}$ \\
\hline
\end{tabular}

oxidation peak current on the pulse amplitude was examined in the range of $5 \sim 50 \mathrm{mV}$. From $5 \sim 10 \mathrm{mV}$, the variation of the peak currents with the pulse amplitude increasing was a linear increasing, over $10 \mathrm{mV}$ the variations remained almost constant. Thus, a pulse amplitude of $10 \mathrm{mV}$ was chosen to improve the sensitivity without peak distortion. With a $10 \mathrm{mV}$ pulse amplitude, the frequency was varied in the range from $1 \sim 24 \mathrm{~Hz}$. From the experimental results it was found that from 1 $5 \mathrm{~Hz}$, the peak currents increased linearly with increasing frequency; over $5 \mathrm{~Hz}$, the variation of the currents with the frequency increasing remained almost constant. A frequency of $5 \mathrm{~Hz}$ was chosen. Also with a $10 \mathrm{mV}$ pulse amplitude and a $5 \mathrm{~Hz}$ frequency, a scan potential increment of $11 \mathrm{mV}$ was found to develop a welldefined peak and a higher current response.

Square Wave Voltammetric Behaviors of VEN The SWV behaviors of $2.0 \times 10^{-4} \mathrm{~mol} \mathrm{L^{-1 }} \mathrm{VEN}$ at MWCNTs-RTIL/GCE, MWCNT/GCE and GCE in $0.10 \mathrm{~mol} \mathrm{~L}^{-1}$ of PBS were investigated respectively as shown in Figure 6. From Figure 6, it can be seen that VEN itself showed a sluggish SWV response at GCE and a less sensitive electrochemical response at MWCNTs/GCE in contrast to that at MWCNTsRTIL/GCE, which revealed a faster electron transferring process of VEN at MWCNTs-RTIL/GCE. The experimental result was in quite good agreement with that of CV.

The catalytic oxidation peak currents $\left(I_{\mathrm{p}}\right)$ for VEN with the variation of its concentrations $(C)$ were investigated at MWCNTs-RTIL/GCE under the optimized experimental conditions (the amplitude $10 \mathrm{mV}$, the frequency $5 \mathrm{~Hz}$, and the scanning potential increment $11 \mathrm{mV}$ ). Linear calibration curves are obtained over the concentration ranges of $2.0 \times 10^{-6} \mathrm{~mol} \mathrm{~L}^{-1} \sim$ $2.0 \times 10^{-3} \mathrm{~mol} \mathrm{~L}^{-1}$ with linear fitting regression equation

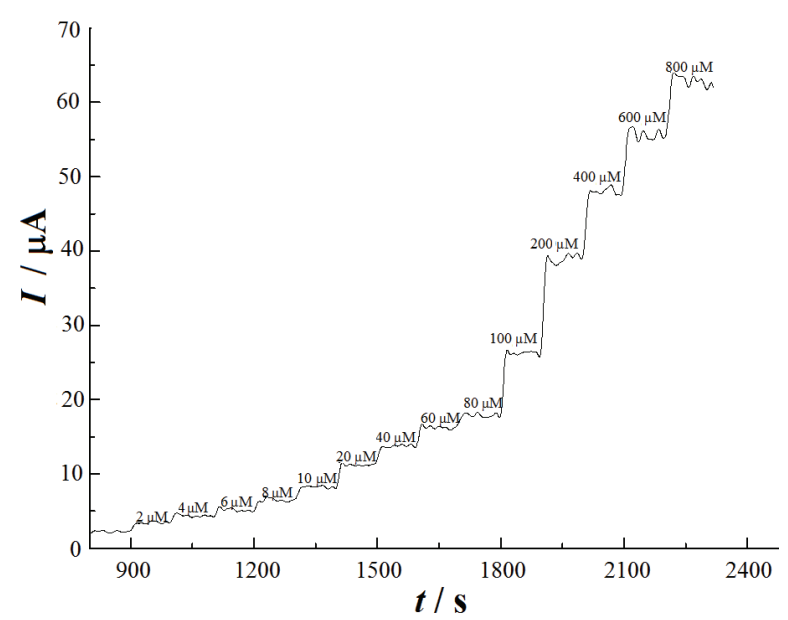

Figure 5. Time-dependent steady state currents obtained at MWCNTs-RTIL/GCE while increasing VEN concentration at $0.80 \mathrm{~V}$ with a stirring rate as $100 \mathrm{rpm}$. 


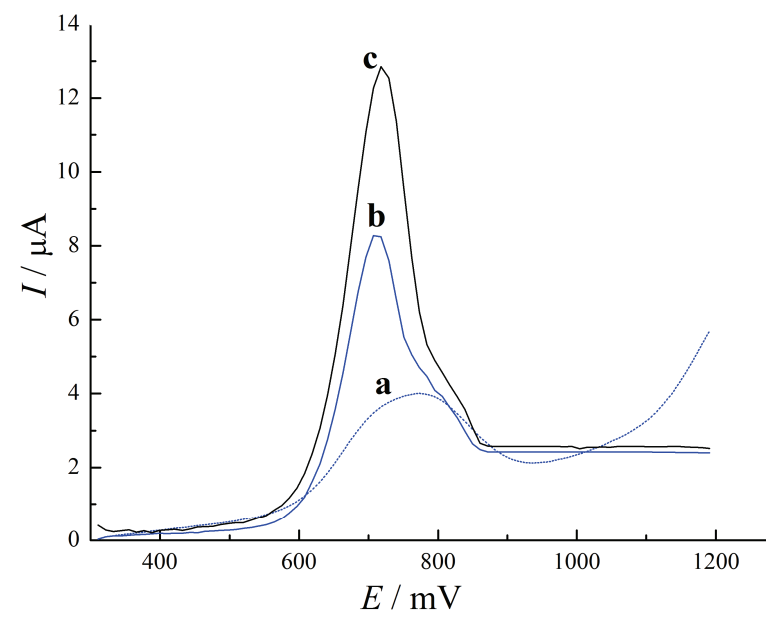

Figure 6. SWVs curves of $2.0 \times 10^{-4} \mathrm{~mol} \mathrm{~L}^{-1} \mathrm{VEN}$ in $0.10 \mathrm{~mol} \mathrm{~L}^{-1} \mathrm{PBS}$ at $\operatorname{GCE}$ (a), MWCNTs/GCE (b) and MWCNTs-RTIL/GCE (c).

as $I_{\mathrm{p}} / \mu \mathrm{A}=0.63+10.54 C\left(10^{-3} \mathrm{~mol} \mathrm{~L}^{-1}\right)$, the correlation coefficient $(R)$ as 0.9999 , the detection limit was $1.69 \times 10^{-6} \mathrm{~mol} \mathrm{~L}^{-1}$ according to $S / N=3$.

Under the optimized experimental conditions, the direct determination of $1.0 \times 10^{-4} \mathrm{~mol} \mathrm{L^{-1 }} \mathrm{VEN}$ in $0.10 \mathrm{~mol} \mathrm{~L}^{-1}$ PBS was checked in the presence of some common compounds or ions found in pharmaceutical preparations. The determination results showed that within a relative error of $\pm 5 \%, 1000$-fold of inorganic ions $\mathrm{K}^{+}, \mathrm{Ca}^{2+}, \mathrm{Cl}^{-}, \mathrm{NO}_{3}^{-}$, 100-fold of starch, glucose, saccharose, magnesium stearate, dextrin, citric acid and tartaric acid does not affect VEN current response.

In order to examine the reproducibility of MWCNTs-RTIL/GCE, ten times of the determinations of $1.0 \times 10^{-4} \mathrm{~mol} \mathrm{L^{-1 }} \mathrm{VEN}$ was performed by one MWCNTs-RTIL/GCE, nearly the same results were obtained. A relative standard deviation (RSD) of $1.4 \%$ was obtained by measuring the oxidation peak currents for VEN electrochemical oxidation using six of the independent MWCNTs-RTIL/GCE. The experimental results showed a good reproducibility of the modified electrodes. The errors of the response current measurement of VEN are within $\pm 5 \%$ after the modified electrode was stored for $48 \mathrm{~h}$ under the room temperature, which suggested the excellent stability of the modified electrode.

The proposed methods were successfully applied in the quantitative determination of VEN content in commercial venlafaxine hydrochloride capsules sample. From the experimental results (as shown in Table 2), it was found that the proposed method afforded $25 \mathrm{mg}$ per capsule with the relative standard deviations (RSD) as $0.2 \% \sim 0.7 \%$, based on the average of the six replicate measurements. The accuracy of the proposed method was also judged by applying the standard VEN sample addition ${ }^{56}$ which a small amount of standard spiking VEN solution of known concentration is added to a portion of a previously analyzed real sample solution in the identical experimental conditions and their mean percentage recoveries are $99.7 \%$ $102.0 \%$. These determination results implied that there were no significant differences between the proposed one and the reported conventional method ${ }^{31-34}$ with respect to reproducibility, accuracy and precision. In other words, the proposed method can provides a convenient and efficient one for the determination of VEN with the advantages of simplicity, sensitivity and the rapidity.

\section{CONCLUSION}

The electrochemical behaviors, electrochemical kinetics and electrochemical determination of VEN were investigated by several electrochemical methods based on the application of the MWCNTs-RTIL/GCE. A welldefined irreversible electrocatalytic oxidation peak of VEN at MWCNTs-RTIL/GCE was obtained. The VEN electrocatalytic oxidation reaction is a diffusioncontrolled process involving two electrons transferring accompanied by two protons taking part in the electrode reaction process. At the same time, the electrochemical kinetic parameters (charge transferring coefficient $\alpha$ and the electrode reaction rate constant $k_{\mathrm{f}}$ ) were determined. From the recovery determined results (RSD as $0.2 \%$ $0.7 \%$, the mean percentage recoveries as $99.7 \%$ $102.0 \%$ ), a good accuracy and precision of the proposed method was obtained. Therefore, the proposed method can be successfully applied in the electrochemical quantitative determination of VEN content in commercial venlafaxine hydrochloride capsules and the determination results could meet the requirement of the quantitative determination.

Acknowledgements. This work was financially supported by The Natural Science Foundation of China (No. 21261018).

Table 2. Determination results of VEN samples $(n=6)$

\begin{tabular}{ccccccc}
\hline Samples & Labeled & Founded / mg & RSD / \% & Added / mg & Found / mg & Recovery / \% \\
\hline 1 & & 25.02 & 0.7 & 15.00 & 39.99 & 99.80 \\
2 & 25.00 mg capsule $^{-1}$ & 24.90 & 0.3 & 20.00 & 45.30 & 102.0 \\
3 & & 24.98 & 0.2 & 25.00 & 49.90 & 99.70 \\
\hline
\end{tabular}




\section{REFERENCES}

1. J. M. Andrews, P. T. Ninan, and C. B. Nemeroff, Depression 4 (1996) 48-56.

2. D. R. Hicks, D. Wolaniuk, A. Russell, N. Cavanaugh, and M. Kraml, Ther. Drug. Monit. 16 (1994) 100-102.

3. S. M. Holliday and P. Benfield, Drugs 49 (1995) 280-294.

4. S. V. Otton, S. E. Ball, S, W. Cheung, T. Inaba, R. L. Rudolph, and E. M. Sellers, Br. J. Clin. Pharmacol. 41 (1996) 149-156.

5. M. Kandasamy, P. Sriniva, K. Subramaniam, S. Ravi, J. John, R. Shekar, N. Srinivas, and S. Thangam, Eur. J. Clin. Pharmacol. 66 (2010) 879-887.

6. S. A. Montgomery, Int. Clin. Psychopharmacol. 10 (1995) 2127.

7. A. Khan, L. F. Fabre, and R. Rudolph, Psychopharmacol. Bull. 27 (1991) 141-144.

8. Y. Lecrubier, Int. Clin. Psychopharmacol. 10 (1995) 29-35.

9. E. B. Asafu-Adjaye, P. J. Faustino, M. A. Tawakkul, L. W. Anderson, L. X. Yu, H. Kwon, and D. A. Volpe, J. Pharm Biomed Anal. 43 (2007) 1854-1859.

10. B. B. Raut, B. L. Kolte, A. A. Deo, M. A. Bagool, and D. B. Shinde, J. Liq. Chromatogr. Relat. Technol. 26 (2003) 12971313.

11. E. M. Clement, J. Odontiadis, and M. Franklin, J. Chromatogr. B 705 (1998) 303-308.

12. W. Liu, H. L. Cai, and H. D. Li, J. Chromatogr. B 850 (2007) 405-411.

13. J. He, Z. L. Zhou, and H. D. Li, J. Chromatogr. B 820 (2005) 33-39.

14. R. L. Vu, D. Helmeste, L. Albers, and C. Reist, J. Chromatogr. B 703 (1997) 195-201.

15. H. D. Li, D. R. Ding, B. K. Zhang, and H. Y. Yuan, Chin. J. Pharm. Anal. 21 (2001) 240-306.

16. J. Meng, X. L. Sun, X. Y. Qin, X. Y. Li, A. L. Zhang, and A. D. Wen, Chin. J. Pharm. Anal. 28 (2008) 1442-1445.

17. J. Bhatt, A. Jangid, G. Venkatesh, G. Subbaiah, and S. Singh, J. Chromatogr. B. 829 (2005) 75-81.

18. W. Zhang, B. R. Xiang, and C. Y. Wang, Biomed. Chromatogr. 21 (2007) 266-272.

19. A. D. Castro, M. Concheiro, O. Quintela, A. Cruz, and M. Lopez-rivadulla, J. Pharm Biomed. Anal. 48 (2008) 183-193.

20. H. B. Theron, M. J. Merwe, K. J. Swart, and J. H. Westhuizen, Rapid. Commun. Mass. Spectrom. 21 (2007) 1680-1686.

21. G. R. Shah, B. T. Thaker, K. R. Surati, and M. H. Parabla, Anal. Sci. 25 (2009) 1207-1210.

22. F. Donata, S. Giulia, V. Susanna, F. Giampietro, T. Daniele, C. Franca, and F. S. Davide, Ther. Drug Monit. 32 (2010) 30-39.

23. S. N. Makhija and P. R. Vavia, J. Pharm Biomed. Anal. 28 (2002) 1055-1059.

24. L. S. Bernardi, P. R. Oliveira, F. S. Murakami, S. H. M. Borgmann, M. Z. Arend, and S. G. Cardoso, J. Chromatogr. Sci. 47 (2009) 770-776.

25. R. Sundaraganapathy, M. Jambulingam, T. S. Ananda, and U. Subasini, J. Pharm Ind. Res. 1 (2011) 28-31.

26. B. F. Joerg and H. M. Hans, Ther. Drug Monit. 23 (2001) 61-70.

27. R. Nageswara Rao and A. Narasa Raju, J. Sep. Sci. 29 (2006) 2733-2744

28. S. L. Baldania, K. K. Bhatt, R. S. Mehta, D. A. Shah, and T. R.
Gandhi, Indian. J. Pharm. Sci. 70 (2008) 124-128.

29. M. Vidyavathi, D. R. Krishna, K. V. S. R. G. Prasad, and J. Vidyasagar, Curr. Trends Biotechnol Pharm. 3 (2009) 64-70.

30. S. Rudaz, C. Stella, A. E. Balant-Gorgia, S. Fanali, and J. L. Veuthey, J. Pharm Biomed. Anal. 23 (2000) 107-115.

31. J. L. F. C. Lima, D. V. Loo, C. Delerue-Matos, and A. S. Roque da Silva, Il Farmaco 54 (1999) 145-148.

32. S. Morais, C. P. M. C. A. Ryckaert, and C. Delerue-Matos, Pharm Anal. 36 (2003) 2515-2526.

33. B. J. Sanghavi and A. K. Srivastava, Electrochim. Acta 56 (2011) 4188-4196.

34. J. W. Chen, C. Q. Duan, and Z. N. Gao, Chin J Pharm Anal. 32 (2012) 515-519.

35. S. Lijima, Nature 354 (1991) 56-58.

36. Y. K. Kwon and D. Tomanek, Phys. Rev. B. 58 (1998) 1600116004.

37. C. Schonenberger and L. Forro, Phys. World 13 (2000) 1-5.

38. H. L. Qi and C. X. Zhang, Electroanalysis 17 (2005) 832-838.

39. J. X. Wang, M. X. Li, Z. J. Shi, and N. Q. Li, Anal Chem. 74 (2002) 1993-1997.

40. J. M. Nugent, K. S. V. Santhanam, A. Rubio, and P. M. Ajayan, Nano. Lett. 1 (2001) 87-91.

41. H. Y. Xiong, Y. F. Zhao, P. Liu, X. H. Zhang, and S. F. Wang, Microchim. Acta 168 (2010) 31-36.

42. J. G. Huddleston and R. D. Rogers, Chem. Commun. 16 (1998) 1765-1766.

43. Y. X. Sun, J. J. Fei, J. Hou, Q. Zhang, Y. L. Liu, and B. N. Hu, Microchim. Acta 165 (2009) 373-379.

44. Q. Zhao, D. P. Zhan, H. Y. Ma, M. Q. Zhang, Y. F. Zhao, P. Jing, and Z. W. Zhu, Front. Biosci. 10 (2005) 326-334.

45. Y. F. Zhao, Y. Q. Gao, D. P. Zhan, H. Liu, Q. Zhao, Y. Kou, Y. H. Shao, M. X. Li, and Q. K. Zhuang, Talanta 66 (2005) 51-57.

46. Y. Zhao, H. Liu, Y. Kou, M. Li, Z. Zhu, and Q. Zhuang, Electrochem. Commun. 9 (2007) 2457-2462.

47. Z. W. Zhao, Z. P. Guo, and J. Ding, Electrochem. Commun. 8 (2006) 245-250.

48. H. B. Kim, J. S. Choi, S. T. Lim, H. J. Choi, and H. S. Kim, Synt Met. 154 (2005) 189-192.

49. T. Fukushima, A. Kosaka, Y. Ishimura, T. Yamamoto, T. Takigawa, N. Ishii, and T. Aida, Science 300 (2003) 2072-2074.

50. X. M. Zhan, L. H. Liu, and Z. N. Gao, J. Solid State Electrochem. 15 (2011) 1185-1192.

51. S. C. Tsang, Y. K. Chen, P. J. F. Harris, and M. L. H. Green, Nature 372 (1994) 159-162.

52. J. J. Feng, G. Zhao, J. J. Xu, and H. Y. Chen, Anal. Biochem. 342 (2005) 280-286.

53. E. Barsoukov and J. R. Macdonald (Eds), Impedance spectroscopy: theory, experiment, and applications, $2^{\text {nd }}$ Ed. John Wiley \& Sons Inc, New Jersey, 2005.

54. S. M. Golabi and H. R. Zare, Electroanalysis 11 (1999) 1293 1300 .

55. H. Q. Wu and Y. F. Li, Electrochemical kinetics, China Higher Education Press, Beijing and Springer, Verlag Berlin Heidelberg, 1998, pp 96-100.

56. Hobart H. Willard, Lynne L. Merritt, JR, John A. Dean, and Frank A. Settle JR: Instrumental Methods of Analysis, Sixth Edition, Wadsworth Publishing Company, Belmont, California, 1981, pp 866-867. 